А.А. Протасов. - Саратов, 2005. - 355 с.

10. Рейнгарт Э.С. Обоснование параметров и разработка машин для уборки корнеплодов и лука: дис. ... д-ра техн. наук: 05.20.01 / Э.С. Рейнгарт. - М., 1995. - 38 с.

11. Сибирёв А.В., Аксенов А.Г., Дорохов А.С. Уточненный расчет сепарирующей поверхности машины для уборки лука // Сельскохозяйственные машины и технологии. - 2018. - № 3. C. 20-24.

12. Сорокин А.А. Теория и расчет картофелеуборочных машин. - М., 2006. - 159 с.

Сибирёв Алексей Викторович, канд. техн. наук, старший научный сотрудник отдела техно- логий и машин в овощеводстве, Федеральный научный агроинженерный центр ВИМ, Россия.

Аксенов Александр Геннадьевич канд. техн. наук, зав. отделом технологий и машин в овощеводстве Федеральный научный агроинженерный центр ВИМ, Россия.

Дорохов Алексей Семенович, $\partial-p$ техн. наук, илен-корреспондент РАН, Федеральный научный агроинженерный центр ВИМ, Россия.

109428, г. Москва, 1-й Институтский проезд, 5. Тел.: (499) 174-89-11.

Ключевъе слова: конструктивные параметры; технологические параметры; лук; диаметр вальиза; ширина вальиа; плотность почвы.

\title{
RESULTS OF THEORETICAL RESEARCHES OF THE CONSTRUCTIVE PARAMETERS OF THE CYLINDRICAL ROLLER OF ONIONS HARVESTING MACHINE
}

Sibiriev Aleksey Viktorovich, Candidate of Technical Sciences, Senior Researcher, Department of Technology and Machines in Vegetable Farming, Agroengineering Center VIM, Russia.

Aksenov Alexander Gennadievich, Candidate of Technical Sciences, Head of the Department of Technology and Machines in Vegetable Farming Agroengineering Center VIM, Russia.

Dorokhov Alexei Semenovich, Doctor of Technical Sciences, Corresponding Member of the Russian Academy of Sciences, Agroengineering Center VIM, Russia.

Keywords: constructive parameters; technological pa- rameters; onion; roll diameter; roll width, soil density.

The technological process of operation of a cylindrical bad-shaping roller of onion harvesting machine has been theoretically studied. The technological and design parameters of the cylindrical bad-shaping roller have been determined. They have a limiting effect on the operation of the machine for onion harvesting. They are diameter, width and rotational speed of the cylindrical bad-shaping roller, traction force, contact area and pressure of the cylindrical bad-shaping roller on the soil.

удк 696.2

\section{АНАЛИЗ ИЗМЕНЕНИЯ ДАВЛЕНИЯ В ГАЗОВЫХ СЕТЯХ}

\author{
СОЛОВЬЕВА Елена Борисовна, Национальный исследовательский Московский \\ государственный строительный университет
}

В работе рассмотрены различные колебания давления газа у потребителей, которые зависят от величины расчетного перепада и степени его использования на пути движения газа от точки питания до газоиспользующей установки.

Введение. При сжигании газовоздушной смеси при стехиометрическом составе возникает ряд трудностей, связанных с устойчивостью процесса горения. Нарушение устойчивости горения может произойти в случае проскока или отрыва пламени. Угроза проскока или отрыва пламени возникает при увеличении доли первичного воздуха в газовоздушной смеси и приближении ее по составу к стехиометрической. Наиболее устойчивым является диффузионное горение, когда весь необходимый для него воздух поступает непосредственно в зону горения. Возможные пределы устойчивой работы газогорелочных устройств широки. Диффузия вторичного воздуха к потоку газа не зависит от скорости потока. С увеличением доли первичного воздуха пределы устойчивого процесса горения сокращается и при подачи смеси стехиометрического состава они сужаются на столько, что малешее нарушение нагрузки горелки приводит либо к отрыву, либо проскоку пламени $[1,2]$.

Чтобы обеспечить устойчивый процесс горения, необходимо поддерживать скорость входа газовоздушной смеси в определенном 
соотношении от скорости распределения пламени. При несоблюдении этих соотношений стабильная работа газогорелочного устройства нарушается. Поэтому очень важно поддерживать стабильное нормальное давление перед газогорелочным устройством. Во избежание проскока пламени нужно, чтобы скорость истечения была всегда выше скорости распространения пламени.

Потребители к газовым сетям низкого давления подключаются непосредственно. При поддержании номинального давления перед газовым прибором горелки работают устойчиво без отрыва и проскока пламени и обеспечивают полноту сгорания газа с максимальным значением коэффициента полезного действия[3].

Колебания давления газа у агрегатов зависят от - величины расчетного перепада давления и степени его использования на пути движения газа от точки питания до газоиспользующей установки; режима работы газоиспользующих установок; метода регулирования давления газа в точке питания сети $[4,8]$.

Методика исследований. Бытовые газовые приборы выпускаются для двух номинальных давлений газа $P_{\text {ном }}=1274$ и 1960 Па.

Максимальные колебания давления газа перед приборами равны расчетному перепаду давления газа для газовой сети $[5,9]$.

Определим перегрузку газовых приборов на основе нормативных данных для номинального давления газа $P_{\text {ном }}=1274$ и 1960 Па.

$$
\begin{aligned}
& K_{1}=\frac{P_{\text {max }}}{P_{\text {нон }}}=\frac{1764}{1274}=1,4 ; \\
& K_{1}=\frac{P_{\text {max }}}{P_{\text {но }}}=\frac{2744}{1960}=1,4 .
\end{aligned}
$$

Рассчитаем нагрузку газовых приборов на основе нормативных данных для номинального давления 1960 Па и 1274 Па:

$$
\begin{aligned}
& K_{2}=\frac{P_{\text {min }}}{P_{\text {но }}}=\frac{980}{1960}=0,5 ; \\
& K_{2}=\frac{P_{\text {min }}}{P_{\text {но }}}=\frac{697}{1274}=0,5 .
\end{aligned}
$$

Исходя из максимальных колебаний давлений газа перед установками расчетный перепад давления для сети будет равен:

$$
\begin{gathered}
\Delta P_{0}=P_{\text {max }}-P=\left(K_{1}-K_{2}\right) P_{\text {нот }}= \\
=(1,4-0,5) P_{\text {Hon }}=0,9 P_{\text {HorI }} .
\end{gathered}
$$

Таким образом при номинальном давлении $P_{\text {ном }}=1274$ Па расчетный перепад давления равен:

$$
\Delta P_{p}=0,9 \cdot 1274=1147 \text { Па }
$$

При номинальном давлении $P_{\text {ном }}=1960$ Па расчетный перепад давления равен:

$$
\Delta P_{\mathrm{p}}=0,9 \cdot 1960=1764 \text { Па. }
$$

Согласно СП 42-101-2003, расчетные суммарные потери давления газа в газопроводах низкого давления (от источника газоснабжения до наиболее удаленного прибора) принимается не более 1800 Па.

Таким образом для газовых приборов с номинальным давлением $P_{\text {ном }}=1960$ Па нормативные данные из СП 42-101-2003 полностью совпадают, а для газовых агрегатов с номинальным давлением $P_{\text {ном }}=1274$ Па значение расчетного перепада (1147 Па) значительно отличается от нормативного значения. В этом случае газовые приборы будут работать с перегрузкой и недогрузкой и это отразится на устойчивости работы агрегатов.

Уравнение, связывающее значение начального давления $P_{\text {н }}$ в сети, давление у потребителя $\mathrm{P}_{\text {п }}$ и перепад давления при расчетном режиме $\Delta P_{p}[5,9]$ :

$$
P_{\text {I }}=P_{\text {II }}+\beta \Delta P_{p},
$$

где $\beta$ - степень использования расчетного перепада давления газа.

С учетом изменения нагрузки по отношению к максимальной $\left(\frac{Q}{Q_{\max }}\right)^{1,8}=x^{1,8}$ получа-
ем уравнение:

$$
P_{\text {в }}=P_{\text {II }}+\beta x^{1,8} \Delta P_{p} .
$$

Считая начальное давление в сети постоянным и равным $P_{\text {н }}=1,4 P_{\text {ном }}$ и принимая расчетный перепад давления газа $\Delta P_{\mathrm{p}}=0,9 P_{\text {ном}}$, уравнение принимает следующий вид:

$$
1,4 P_{\text {ном }}=P_{\text {II }}+\beta x^{1,8} 0,9 \Delta P_{p} .
$$

Давление газа перед приборами потребителей находят из выражения

$$
\begin{gathered}
P_{\text {I }}=1,4 P_{\text {нолт }}-\beta x^{1,8} 0,9 \Delta P_{p}= \\
=P_{\text {нот }}\left(1,4-\beta x^{1,8} 0,9\right) .
\end{gathered}
$$

Определим значения давления газа у потребителей при полном использовании расчетного перепада давления $\beta=1, \beta=0,5$ и возможных изменений нагрузки $x$ от 0,1 до 1 .

Результаты исследований. Анализ табл. 1, 2 и графика (см. рисунок) показывает, что основная часть нагрузок газовой сети не превышает максимально допустимых ве- 
личин. Это давление газа 1764 Па при номинальном давлении $P_{\text {ном }}=1274$ Па, и давление 2744 Па при номинальном давлении газа 1960 Па. Таким образом для потребителей, запроектированных на номинальное давление 1960 Па, давление газа перед газовыми горелками при любом изменении нагрузки не превышает максимальное давление 2744 Па [6, 7].

У потребителей газа, у которых газовые приборы выпущены на номинальное давление $P_{\text {ном }}=1274$ Па, давление газа при изменении нагрузки будет превышать максимальное давление $P_{\max }=2744$ Па только при $x=0,1$ и $x=0,2$ увеличение давления достигнет величин 1771 и 1752 Па соответственно.

Заключение Анализ давлений газа у потребителей, которые изготовлены на различное номинальное давление, показал неоднозначное реагирование на изменение давления. Учитывая изменение давления газоиспользующих установок у потребителей необходимо регулировать выходное давление из газорегуляторного пункта в соответствие с нагрузкой сети. Начальное давление в сети надо поддерживать таким, чтобы давление у потребителей при всех режимах работы было равно номинальному.

\section{СПИСОК ЛИТЕРАТУРЫ}

1. ГОСТ 54961-2012. Газораспределительная система. Сети потребления газа. Общие требования к эксплуатации. Эксплуатационная документация. - М., 2012.

2. Жила В.А. Газоснабжение. - М.. 2014. - 472 с.

3. Жила В.А., Соловъева Е.Б., Гулюкин Д.М. Безопасность систем газоснабжения и газорас-

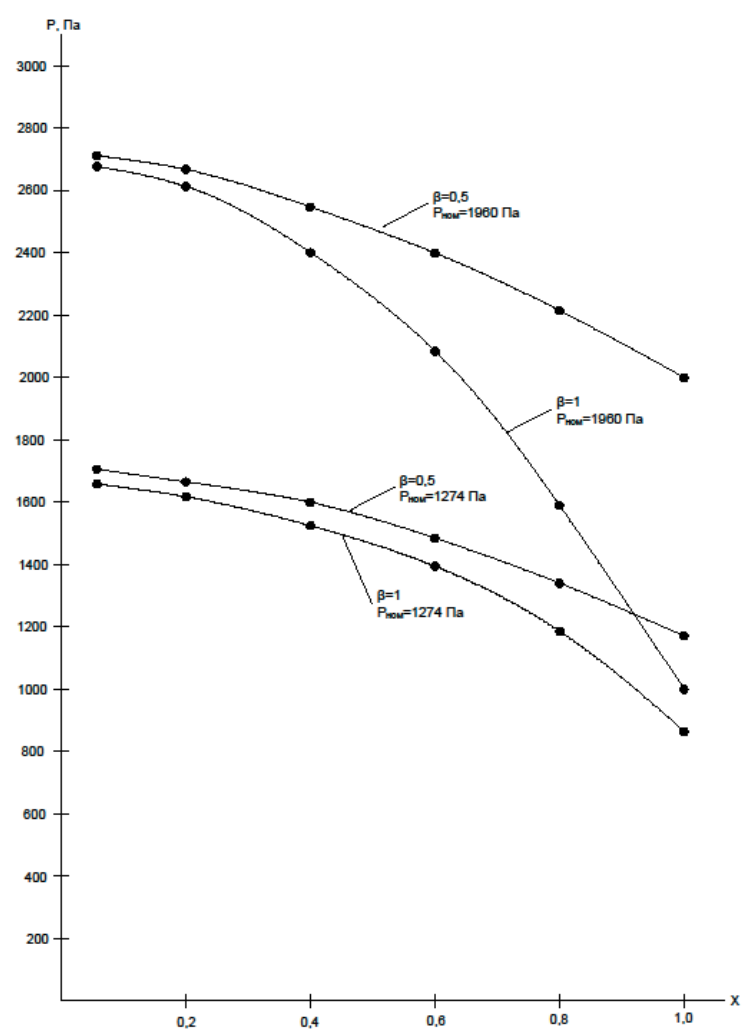

Изменение давления газа у потребителей при различных нагрузках и степени использования расчетного перепада

пределения // Научное обозрение. - 2016. № 22. - C. 27-32.

4. Жила В.А., Соловъева Е.Б., Маркевич Ю.Г. Разработка методики определения оптимальных показателей надежности элементов систем газоснабжения. - М., 2016.

5. О мерах по обеспечению безопасности при эксплуатации и обслуживании внутреннего и внутриквартирного газового оборудования: Постановление Правительства Российской Федерации от 14 мая 2013 года // СПС «Гарант».

6. Об утверждении Технического регламента O безопасности сетей газораспределения и газопотребления: Постановление Правительства Россий-

Таблица 1

Давление газа у потребителей при изменении нагрузки и степени использования расчетного перепада давления при $P_{\text {ном }}=1960$ Па

\begin{tabular}{|c|c|c|c|c|c|c|}
\hline \multicolumn{7}{|c|}{ При $\beta=1$} \\
\hline$x$ & 0,1 & 0,2 & 0,4 & 0,6 & 0,8 & 1,0 \\
\hline$P_{\pi}$, Па & 2705 & 2646 & 2391 & 2038 & 1568 & 980 \\
\hline \multicolumn{7}{|c|}{ При $\beta=0,5$} \\
\hline$P_{\pi}$, Па & 2724 & 2696 & 2575 & 2391 & 2156 & 1862 \\
\hline
\end{tabular}

Таблица 2

Давление газа у потребителей при изменении нагрузки и степени использования расчетного перепада давления при $P_{\text {ном }}=1274$ Па

\begin{tabular}{|c|c|c|c|c|c|c|}
\hline \multicolumn{7}{|c|}{ При $\beta=1$} \\
\hline$x$ & 0,1 & 0,2 & 0,4 & 0,6 & 0,8 & 1,0 \\
\hline$P_{n}$, Па & 1758 & 1720 & 1564 & 1325 & 1019 & 637 \\
\hline \multicolumn{7}{|c|}{ При $\beta=0,5$} \\
\hline$P_{n}$, Па & 1771 & 1752 & 1674 & 1554 & 1401 & 1210 \\
\hline
\end{tabular}


ской Федерации от 29 октября 2010 года // СПС «Гарант».

7. Системы газораспределения. Сети газопотребления. Общие требования к эксплуатации. Эксплуатационная документация. Национальный стандарт РФ. ГОСТ 54961. - М., 2012.

8. Соловъева Е.Б., Харламова Н.А. Определение объема выбросов газа из мест расположения надземных газопроводов // Научное обозрение. 2013. - № 5. - С. 94-98.

9. СП 42.101.2003. Общие положения по проектированию и строительству газораспредели- тельных систем из металлических и полиэтиленовых труб. - М., 2004.

Соловьева Елена Борисовна, канд. техн. наук, доцент кафедры «Теплогазоснабжение и вентиляция», Национальный исследовательскийМосковский государственный строительный университет, Россия.

129337, г. Москва, Ярославское шоссе, 26.

Тел.: (495) 781-80-07.

Ключевые слова: низкое давление; потребители; расчетный перепад давления; газ; газовые приборы.

\title{
ANALYSIS OF PRESSURE CHANGES IN GAS NETWORKS
}

Solovyeva Elena Borisovna, Candidate of Technical Sciences, Associate Professor of the chair "Heat and Gas Supply and Ventilation", Moscow State University of Civil Engineering. Russia.

Keywords: low pressure; consumers; calculated pressure drop; gas; gas appliances.
The paper considers various fluctuations in gas pressure at consumers, which depend on the magnitude of the calculated differential and the degree of its use in the path of gas movement from the feed point to the gas-using unit.

удК 697.2

\section{ТЕПЛОМАССОПЕРЕНОС В КОНДЕНСАЦИОННЫХ ТЕПЛОГЕНЕРАТОРАХ МАЛОЙ МОЩНОСТИ}

\author{
ЧУЛЕНЁВ Анатолий Сергеевич, Нацииональный исследовательский Московский \\ государственный строительный университет
}

Рассматривается и анализируется физико-математическая модель теплообмена на поверхностях конденсации котлов. Проведены исследования профилей температур и парииального давления компонентов, содержащихся в потоке продуктов сгорания на поверхности конденсащии. Для физико-математических модельных критериев получены обобщенные и частные зависимости (для конкретных конструкций теплообменных устройств). Получены качественные стандарты влияния критериев на общую производительность конденсационных поверхностей нагрева котлов малой мощцости.

Введение. Термодинамические процессы тепло- и массопереноса в конденсационных поверхностях нагрева (имеющих низкую температуру) конденсационных теплогенераторов малой мощности зависят от интенсивности процесса конденсации водяных паров из дымовых газов и сопровождаются теплопереносом при переносе массы, что объясняется переносом явной теплоты и выделением скрытой теплоты парообразования.

Рассматривая конденсационную часть теплообменника теплогенератора, можем утверждать, что конденсация будет происходить на охлаждаемой поверхности, тем- пература которой должна быть меньше температуры точки росы продуктов сгорания топлива (т.е. температуры насыщения при постоянном давлении). На поверхности при этом образуется пленка конденсата [6].

Методика исследований. Разработка физической модели тепломассопереноса при кратковременном описании процесса может быть рассмотрена для слоя $d x \cdot l z$ плоскости, движущейся в канале дымовых газов. Таким образом, имеет место тепломассоперенос на поверхности конденсатной пленки с образованием условного пограничного слоя в потоке дымовых газов. 